\title{
Serotonin-mediated anxiety: How to recognize and treat it
}

\section{Sara R. Abell, MD, and Rif S. El-Mallakh, MD}

ndividuals with anxiety will experience frequent or chronic excessive worry, nervousness, a sense of unease, a feeling of being unfocused, and distress, which result in functional impairment. ${ }^{1}$ Frequently, anxiety is accompanied by restlessness or muscle tension. Generalized anxiety disorder is one of the most common psychiatric diagnoses in the United States and has a prevalence of $2 \%$ to $6 \%$ globally. ${ }^{2}$ Although research has been conducted regarding anxiety's pathogenesis, to date a firm consensus on its etiology has not been reached. ${ }^{3}$ It is likely multifactorial, with environmental and biologic components.

One area of focus has been neurotransmitters and the possible role they play in the pathogenesis of anxiety. Specifically, the monoamine neurotransmitters have been implicated in the clinical manifestations of anxiety. Among the amines, normal roles include stimulating the autonomic nervous system and regulating numerous cognitive phenomena, such as volition and emotion. Many psychiatric medications modify aminergic transmission, and many current anxiety medications target amine neurotransmitters. Medications that target histamine, serotonin, norepinephrine, and dopamine all play a role in treating anxiety.

In this article, we focus on serotonin (5-hydroxytryptamine, 5-HT) as a mediator of anxiety and on excessive synaptic 5 -HT as the cause of anxiety. We discuss how 5-HT-mediated anxiety can be identified and offer some solutions for its treatment.

\section{The amine neurotransmitters}

There are 6 amine neurotransmitters in the CNS. These are derived from tyrosine (dopamine [DA], norepinephrine [NE], and epinephrine), histidine (histamine), and tryptophan (serotonin [5-HT] and melatonin). In addition to their physiologic actions, amines have been implicated in both acute and chronic anxiety. Excessive DA stimulation has been linked with fear ${ }^{4,5}$; NE elevations are central to hypervigilance and hyperarousal of posttraumatic stress disorder ${ }^{6}$; and histamine may mediate emotional memories involved in fear and anxiety. ${ }^{7}$ Understanding the normal function of 5-HT will aid in understanding its potential problematic role (Box, ${ }^{8-18}$ page 38$)$.

\section{How serotonin-mediated anxiety presents}

"Anxiety" is a collection of signs and symptoms that likely represent multiple processes and have the common characteristic of being subjectively unpleasant, with a subjective wish for the feeling to end. The expression of anxiety disorders is quite diverse and ranges from brief episodes such

Dr. Abell is a PGY-1 Psychiatry Resident, Department of Psychiatry and Behavioral Sciences, University of Louisville School of Medicine, Louisville, Kentucky. Dr. El-Mallakh is Professor and Director, Mood Disorders Research Program, Department of Psychiatry and Behavioral Sciences, University of Louisville School of Medicine, Louisville, Kentucky.

Disclosures

Dr. Abell reports no financial relationships with any companies whose products are mentioned in this article, or with manufacturers of competing products. Dr. El-Mallakh is a speaker for Eisai, Intra-Cellular Therapies, Indivior, Janssen, Lundbeck, Noven, Otsuka, Sunovion, and Teva.

doi: $10.12788 /$ cp. 0168

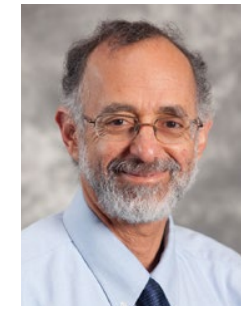

Rif S. El-Mallakh, MD Department Editor

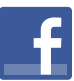

Discuss this article at www.facebook.com/ MDedgePsychiatry 


\section{Clinical Point}

\section{Serotonin-mediated anxiety appears to occur when levels of 5-HT (or stimulation of 5-HT receptors) are particularly high}

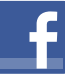

Discuss this article at www.facebook.com/ MDedgePsychiatry

\section{Box}

\section{A closer look at serotonin}

$S^{e}$ rotonin (5-HT) arises from neurons in he raphe nuclei of the rostral pons and projects superiorly to the cerebral cortex and inferiorly to the spinal cord..$^{8}$ It works in an inhibitory or excitatory manner depending on which receptors are activated. In the periphery, 5-HT influences intestinal peristalsis, sensory modulation, gland function, thermoregulation, blood pressure, platelet aggregation, and sexual behavior, ${ }^{9}$ all actions that produce potential adverse effects of serotonin reuptakeinhibiting antidepressants. In the CNS, 5-HT plays a role in attention bias; decision-making; sleep and wakefulness; and mood regulation. In short, serotonin can be viewed as mediating emotional motivation. ${ }^{10}$

Serotonin alters neuroplasticity. During development, 5-HT stimulates creation of new synapses and increases the density of synaptic webs. It has a direct stimulatory effect on the length of dendrites, their branching, and their myelination. ${ }^{11}$ In the CNS, it plays a role in dendritic arborization. Animal studies with rats have shown that lesioning highly concentrated 5-HT areas at early ages resulted in an adult brain with a lower number of neurons and a less complex web of dendrites. ${ }^{12,13}$ In situations of emotional stress, it is theorized that low levels of 5-HT lead to a reduced ability to deal with emotional stressors due to lower levels of complexity in synaptic connections.

Serotonin has also been implicated in mediating some aspects of dopamine-related actions, such as locomotion, reward, and threat avoidance. This is believed to contribute to the beneficial effect of 5-HT2A blockade by secondgeneration antipsychotics (SGAs). ${ }^{14}$ Blockade of other 5-HT receptors, such as 5-HT1A, 5-HT2C,
5-HT6, and 5-HT7, may also contribute to the antipsychotic action of SGAs. ${ }^{14}$

Serotonin receptors are found throughout the body, and 14 subtypes have been identified. ${ }^{9}$ Excitatory and inhibitory action of 5-HT depends on the receptor, and the actions of 5-HT can differ with the same receptor at different concentrations. This is because serotonin's effects are biphasic and concentration-dependent, meaning that levels of 5-HT in the synapse will dictate the downstream effect of receptor agonism or antagonism. Animal models have shown that low-dose agonism of 5-HT receptors causes vasoconstriction of the coronary arteries, and high doses cause relaxation. This response has also been demonstrated in the vasculature of the kidneys and the smooth muscle of the trachea. Additionally, 5-HT works in conjunction with histamine to produce a biphasic response in the colonic arteries and veins in situations of endothelial damage. ${ }^{15}$

Most relevant to this discussion are 5-HT's actions in mood regulation and behavior. Low 5-HT states result in less behavioral inhibition, leading to higher impulse control failures and aggression. Experiments in mice with deficient serotonergic brain regions show hypoactivity, extended daytime sleep, anxiety, and depressive behaviors. ${ }^{13}$ Serotonin's behavioral effects are also biphasic. For example, lowdose antagonism with trazodone of 5-HT receptors demonstrated a pro-aggressive behavioral effect, while high-dose antagonism is anti-aggressive. ${ }^{15}$ Similar biphasic effects may result in either induction or reduction of anxiety with agents that block or excite certain 5-HT receptors. ${ }^{16-18}$ as panic attacks (which may be mediated, in part, by epinephrine/ $\mathrm{NE}^{19}$ ) to lifelong stereotypic obsessions and compulsions (which may be mediated, in part, by DA and modified by 5-HT ${ }^{20,21}$ ). Biochemical separation of the anxiety disorders is key to achieving tailored treatment. ${ }^{6}$ Towards this end, it is important to investigate the phenomenon of serotonin-mediated anxiety.

Because clinicians are familiar with reductions of anxiety as selective serotonin reuptake inhibitors (SSRIs) increase 5-HT levels in the synapse, it is difficult to conceptualize serotonin-mediated anxiety.
However, many of the effects at postsynaptic 5-HT receptors may be biphasic. ${ }^{15-18}$ Serotonin-mediated anxiety appears to occur when levels of 5-HT (or stimulation of 5-HT receptors) are particularly high. This is most frequently seen in patients who genetically have high synaptic 5-HT (by virtue of the short form of the 5-HT transporter), ${ }^{22}$ whose synaptic 5-HT is further increased by treatment with an SSRI, 23 and who are experiencing a stressor that yet further increases their synaptic 5-HT.24 However, it may occur in some individuals with only 2 of these 3 conditions. 
Clinically, individuals with serotoninmediated anxiety will usually appear calm. The anxiety they are experiencing is not exhibited in any way in the motor system (ie, they do not appear restless, do not pace, muscle tone is not increased, etc.). However, they will generally complain of an internal agitation, a sense of a negative internal energy. Frequently, they will use descriptions such as "I feel I could jump out of my skin." As previously mentioned, this is usually in the setting of some environmental stress, in addition to either a pharmacologic (SSRI) or genetic (short form of the 5-HT transporter) reason for increasing synaptic 5-HT, or both.

Almost always, interventions that block multiple postsynaptic 5-HT receptors or discontinuation of the SSRI (if applicable) will alleviate the anxiety, quickly or more slowly, respectively. Sublingual asenapine, which at low doses can block 5-HT2C (Ki $=0.03 \mathrm{nM}), 5-\mathrm{HT} 2 \mathrm{~A}(\mathrm{Ki}=0.07 \mathrm{nM}), 5-\mathrm{HT} 7$ $(\mathrm{Ki}=0.11 \mathrm{nM}), 5-\mathrm{HT} 2 \mathrm{~B}(\mathrm{Ki}=0.18 \mathrm{nM})$, and 5-HT6 $(\mathrm{Ki}=0.25 \mathrm{nM}){ }^{25,26}$ and which will produce peak plasma levels within $10 \mathrm{~min}$ utes, ${ }^{27}$ usually is quite effective. ${ }^{28}$

\section{A key difference: No motor system involvement}

What distinguishes 5-HT from the other amine transmitters as a mediator of anxiety is the lack of involvement of the motor system. Multiple studies in rats illustrate that exogenously augmenting 5-HT has no effect on levels of locomotor activity. Dopamine depletion is well-characterized in the motor dysfunction of Parkinson's disease, and DA excess can cause repetitive, stereotyped movements, such as seen in tardive dyskinesia or Huntington's disease. ${ }^{8}$ In humans, serotonin-mediated anxiety is usually without a motoric component; patients appear calm but complain of extreme anxiety or agitation. Agitation has been reported after initiation of an SSRI, ${ }^{29}$ and is more likely to occur in patients with the short form of the 5-HT transporter..$^{30}$ Motoric activation has been reported in some of these studies, but does not seem to cluster with the complaint of agitation. ${ }^{29}$ The reduced number of available transporters means a chronic steadystate elevation of serotonin, because less serotonin is being removed from the synapse after it is released. This is one of the reasons patients with the short form of the 5-HT transporter may be more susceptible to serotonin-mediated anxiety.

\section{What you need to keep in mind}

Pharmacologic treatment of anxiety begins with an SSRI, a serotonin-norepinephrine reuptake inhibitor (SNRI), or buspirone. Second-line treatments include hydroxyzine, gabapentin, pregabalin, and quetiapine. ${ }^{3,31}$ However, clinicians need to be aware that a fraction of their patients will report anxiety that will not have any external manifestations, but will be experienced as an unpleasant internal energy. These patients may report an increase in their anxiety levels when started on an SSRI or SNRI. 29,30 This anxiety is most likely mediated by increases of synaptic 5-HT. This occurs because many serotonergic receptors may have a biphasic response, so that too much stimulation is experienced as excessive internal energy. ${ }^{16-18}$ In such patients, blockade of key 5-HT receptors may reduce that internal agitation. The advantage of recognizing serotonin-mediated anxiety is that one can specifically tailor treatment to address the patient's specific physiology.

It is important to note that the anxiolytic effect of asenapine is specific to patients with serotonin-mediated anxiety. Unlike quetiapine, which is effective as augmentation therapy in generalized anxiety disorder, ${ }^{31}$ asenapine does not appear to reduce anxiety in patients with schizophrenia ${ }^{32}$ or borderline personality disorder ${ }^{33}$ when administered for other reasons. However, it may reduce anxiety in patients with the short form of the 5-HT transporter. ${ }^{30,34}$

\section{References}

1. Shelton CI. Diagnosis and management of anxiety disorders. J Am Osteopath Assoc. 2004;104(3 Suppl 3):S2-S5.

2. Ruscio AM, Hallion LS, Lim CCW, et al. Cross-sectional comparison of the epidemiology of DSM-5 generalized anxiety disorder across the globe. JAMA Psychiatry. 2017;74(5):465-475.

\section{Clinical Point}

Patients with
serontonin-mediated
anxiety may appear
calm but complain of
extreme anxiety or
agitation




\section{Clinical Point}

Interventions that block multiple postsynaptic 5-HT receptors or discontinuation of the SSRI will alleviate the anxiety

\section{Related Resource}

- Bhatt NV. Anxiety disorders. https://emedicine.medscape. com/article/286227-overview

Drug Brand Names

Asenapine - Saphris,

Secuado

Gabapentin • Neurontin

Hydroxyzine • Vistaril

3. Locke AB, Kirst N, Shultz CG. Diagnosis and management of generalized anxiety disorder and panic disorder in adults. Am Fam Physician. 2015;91(9):617-624

4. Hariri AR, Mattay VS, Tessitore A, et al. Dextroamphetamine modulates the response of the human amygdala. Neuropsychopharmacology. 2002;27(6):1036-1040.

5. Colombo AC, de Oliveira AR, Reimer AE, et al. Dopaminergic mechanisms underlying catalepsy, fear and anxiety: do they interact? Behav Brain Res. 2013;257:201-207.

6. Togay B, El-Mallakh RS. Posttraumatic stress disorder: from pathophysiology to pharmacology. Curr Psychiatry. 2020;19(5):33-39

7. Provensi G, Passani MB, Costa A, et al. Neuronal histamine and the memory of emotionally salient events. Br J Pharmacol. 2020;177(3):557-569.

8. Purves D, Augustine GJ, Fitzpatrick D, et al (eds). Neuroscience. 2nd ed. Sinauer Associates; 2001.

9. Pytliak M, Vargová V, Mechírová V, et al. Serotonin receptors - from molecular biology to clinical applications. Physiol Res. 2011;60(1):15-25.

10. Meneses A, Liy-Salmeron G. Serotonin and emotion, learning and memory. Rev Neurosci. 2012;23(5-6):543-553.

11. Whitaker-Azmitia PM. Serotonin and brain development: role in human developmental diseases. Brain Res Bull. 2001;56(5):479-485

12. Towle AC, Breese GR, Mueller RA, et al. Early postnatal administration of 5,7-DHT: effects on serotonergic neurons and terminals. Brain Res. 1984;310(1):67-75.

13. Rok-Bujko P, Krzścik P, Szyndler J, et al. The influence of neonatal serotonin depletion on emotional and exploratory behaviours in rats. Behav Brain Res. 2012;226(1):87-95.

14. Meltzer HY. The role of serotonin in antipsychotic drug action. Neuropsychopharmacology. 1999;21(2 Suppl): 106S-115S.

15. Calabrese EJ. 5-Hydroxytryptamine (serotonin): biphasic dose responses. Crit Rev Toxicol. 2001;31(4-5):553-561.

16. Zuardi AW. 5-HT-related drugs and human experimental anxiety. Neurosci Biobehav Rev. 1990;14(4):507-510

17. Sánchez C, Meier E. Behavioral profiles of SSRIs in animal models of depression, anxiety and aggression. Are they all alike? Psychopharmacology (Berl). 1997;129(3):197-205.
18. Koek W, Mitchell NC, Daws LC. Biphasic effects of selective serotonin reuptake inhibitors on anxiety: rapid reversal of escitalopram's anxiogenic effects in the novelty-induced hypophagia test in mice? Behav Pharmacol. 2018;29(4): 365-369.

19. van Zijderveld GA, Veltman DJ, van Dyck $R$, et al Epinephrine-induced panic attacks and hyperventilation. J Psychiatr Res. 1999;33(1):73-78.

20. Ho EV, Thompson SL, Katzka WR, et al. Clinically effective OCD treatment prevents 5-HT1B receptor-induced repetitive behavior and striatal activation. Psychopharmacology (Berl). 2016;233(1):57-70.

21. Stein DJ, Costa DLC, Lochner C, et al. Obsessive-compulsive disorder. Nat Rev Dis Primers. 2019;5(1):52.

22. Luddington NS, Mandadapu A, Husk M, et al. Clinical implications of genetic variation in the serotonin transporter promoter region: a review. Prim Care Companion J Clin Psychiatry. 2009;11(3):93-102.

23. Stahl SM. Mechanism of action of serotonin selective reuptake inhibitors. Serotonin receptors and pathways mediate therapeutic effects and side effects. J Affect Disord. 1998;51(3):215-235.

24. Chaouloff F, Berton O, Mormède P. Serotonin and stress. Neuropsychopharmacology. 1999;21(2 Suppl):28S-32S

25. Siafis S, Tzachanis D, Samara M, et al. Antipsychotic drugs: From receptor-binding profiles to metabolic side effects. Curr Neuropharmacol. 2018;16(8):1210-1223.

26. Carrithers B, El-Mallakh RS. Transdermal asenapine in schizophrenia: a systematic review. Patient Prefer Adherence. 2020;14:1541-1551.

27. Citrome L. Asenapine review, part I: chemistry, receptor affinity profile, pharmacokinetics and metabolism. Expert Opin Drug Metab Toxicol. 2014;10(6):893-903.

28. Pratts M, Citrome L, Grant W, et al. A single-dose, randomized, double-blind, placebo-controlled trial of sublingual asenapine for acute agitation. Acta Psychiatr Scand. 2014;130(1):61-68.

29. Biswas AB, Bhaumik S, Branford D. Treatment-emergent behavioural side effects with selective serotonin re-uptake inhibitors in adults with learning disabilities. Hum Psychopharmacol. 2001;16(2):133-137.

30. Perlis RH, Mischoulon D, Smoller JW, et al. Serotonin transporter polymorphisms and adverse effects with fluoxetine treatment. Biol Psychiatry. 2003;54(9):879-883.

31. Ipser JC, Carey P, Dhansay Y, et al. Pharmacotherapy augmentation strategies in treatment-resistant anxiety disorders. Cochrane Database Syst Rev. 2006;(4):CD005473.

32. Kane JM, Mackle M, Snow-Adami L, et al. A randomized placebo-controlled trial of asenapine for the prevention of relapse of schizophrenia after long-term treatment. J Clin Psychiatry. 2011;72(3):349-355.

33. Bozzatello P, Rocca P, Uscinska M, et al. Efficacy and tolerability of asenapine compared with olanzapine in borderline personality disorder: an open-label randomized controlled trial. CNS Drugs. 2017;31(9):809-819.

34. El-Mallakh RS, Nuss S, Gao D, et al. Asenapine in the treatment of bipolar depression. Psychopharmacol Bull. 2020;50(1):8-18.

\section{Bottom Line}

Serotonin-mediated anxiety occurs when levels of synaptic serotonin (5-HT) are high. Patients with serotonin-mediated anxiety appear calm but will report experiencing an unpleasant internal energy. Interventions that block multiple postsynaptic 5-HT receptors or discontinuation of a selective serotonin reuptake inhibitor (if applicable) will alleviate the anxiety. 